\title{
Impact of Language Input on Comprehensiveness of Reading Material among Students in Saudi Arabia
}

\author{
Mohammed Abdulmalik Ali ${ }^{1}$ \\ ${ }^{1}$ Department of English, Prince Sattam bin Abdulaziz University, KSA \\ Correspondance: Mohammed Abdulmalik Ali, Department of English, College of Science \& Humanities, Prince \\ Sattam bin Abdulaziz University, P. O. Box 83, AlKharj, 11942, KSA.
}

Received: October 2, 2018 Accepted: October 25, 2018 Online Published: November 28, 2018

doi:10.5539/ells.v8n4p8 URL: https://doi.org/10.5539/ells.v8n4p8

\begin{abstract}
The aim of the study has been to determine the ways that may facilitate the freshmen at universities, who have English as their second language, with comprehension and understanding of study material. It has included different levels of reading material to the students in order to identify which approach is more convenient for the students to perceive. The approach has concluded that advanced vocabulary and grammatical structure may make it difficult for the students to perceive the meaning of study material. It has been perceived from the study that simplification in the text can bring upon positive impacts on the comprehensibility of content. The comprehensiveness can assist students in learning the study modules yet, it is also presumed that simplification may not enhance the students' capability to comprehend the second language more efficiently. It is expected that further research in the field may give deeper insight of the linguistic modifications that may improve the comprehending abilities of the students.
\end{abstract}

Keywords: reading comprehension, readability, college students, second language learning, simplification

\section{Introduction}

Language skills in the bilingual university students are greatly varied as a result of inconsistency of their language understanding (Hoff \& Core, 2013). Research in second language acquisition (SLA) assures that comprehension of a note by language learners is a critical situation in acquisition process. Similarly, language 'input' in SLA has to be comprehensible for the sake of understanding and achievement. It has been observed that meaning focused instructions are not sufficient to ensure the success in second language learning (Saito \& Saito, 2016). Moreover, many researchers in SLA consider that the cognitive processes, convoluted in language acquisition, are simplicity-oriented. One manifestation is to manage the variations in linguistic data by fitting it into a context of rules and categories that the beginner already holds or has already formulated (Ellis, 2015).

Several researches have indicated that language facilitates comprehension for SL learners and positive effects of syntactic simplification on learners' reading comprehension were also declared useful (Siddharthan, 2016; Mandya et al., 2014; Park \& Warschauer, 2016). Davoudi \& Yousefi (2015) have mentioned that shortening of the sentences will be helpful for the students to improve their reading comprehension. Findings have further elaborated that the simplification of texts is directly associated with the comprehensiveness of sentences. It has been further mentioned that syntactic and organizational simplification features have a positive impact on better reading and writing abilities of the students (Davoudi \& Yousefi, 2015). In particular, the participants' information recall abilities were affected significantly in the favor of syntactic simplification. Similarly, it has been revealed that while simplification facilitated the participants' reading comprehension, it did not considerably benefit the reading comprehension of low-proficiency students (Dell'Orletta, Montemagni, \& Venturi, 2014; Moradian, Naserpoor, \& Tamri, 2013). Similarly, Crossley, Yang \& McNamara (2014) have also retrieved relevant outcomes in regards to the previous study.

Some modern work in text simplification has progressed in sentence compression from research, an associated research field that intends to abbreviate the sentences for the determination of summarizing the main content. Historically, sentence compression has been addressed, where transformation rules are understood from analysed corpora of sentences associated with compressed versions, utilizing ideas taken from the statistical machine translation. The learnt rules of compressions are characteristically syntactic tree-to-tree transformations of some variety. Woodsend and Lapata (2011) developed this type of research. The model is based on QTSG 
(quasi-synchronous tree substitution grammar) and integer linear programming. Woodsend and Lapata (2011) used QTSG to create all probable rewrite operations for a source tree. The proposed system used syntactic and lexical compression as well as simplification.

A study by Crossley et al. (2017) examined the text processing, comprehensions, and familiarity judgment provided by readers utilize a number of diverse approaches; including machine learning and natural language processing. The aim is on the recognition of linguistic features that forecast the readability judgments and how the performance of features is when compared to traditional text readability. The findings indicated that the traditional readability formulas are less analytical than text models of text comprehension, and processing from advanced language processing tools (Crossley et al., 2017).

Sentence simplification aimed to make sentences easier to understand and read. Recent approaches bring visions and understanding from machine translation to learn simplification revisions from monolingual corpora of simple and complex sentences. The simplification problem was addressed with an encoder-decoder model coupled with profound learning outline. The model explored the space of simplifications, optimizing the reward functions that motivate outputs, which are fluent and simple (Zhang \& Lapata, 2017). Research has acknowledged a number of linguistic features that impacts the reading comprehension of new readers; however, limited information is identified about how and whether the findings encompass to adult readers (Crossley et al., 2017).

In the study different ways have been determined that facilitate the freshmen at universities. It has been observed that there are different linguistic features that impact the reading comprehension of the new readers in the educational institutes, who have English as their second language. The overview of different studies showed that students of bilingual universities usually do not comprehend varied languages, as they are inconsistent with the understanding of different languages.

\subsection{Problem Statement}

Language skills in the bilingual university students are considered as the significant factors for building the educational basis. Comprehension abilities of students are highly dependent on the grounds of education. Past literature has indicated that meaning focused instructions are not sufficient for ensuring the success in second language learning. The inconsistency between the provided study material and comprehension of students can create a gap in the educational development. It is thus, necessary to provide the students with several ways that can be comprehensible for them.

\subsection{Research Objective}

The main objective of this research has been to identify the ways that can help the fresh students in universities, who have English as their second language, with comprehending and understanding their study material. The study has considered the problems faced by students due to English language at the educational institutes in Saudi Arabia. The investigation has included different levels of reading material to the students in order to identify which approach is more convenient for the students to perceive.

\section{Method}

The study has implemented quantitative experimental research design. It investigated the differences in the efficiency of reading comprehension among the university students of Saudi Arabia. The target population is comprised of 100 Saudi male students, who began their Preparatory Year Program (PYP) at Prince Sattam bin Abdulaziz University (PSAU), at the first term of the academic year 2014-1015. Their ages ranged between 18 to 20 years. The students have been assessed on the basis of an evaluating test, derived from the standard testing method of British IELTS. Furthermore, students, who scored from $20 \%$ to $40 \%$ in the test, were recruited as the sample population for the study. The freshman population from the Saudi university was assigned randomly to the four treatments that consisted of an activity to read a passage in four levels. The reading comprehension was developed in four manners as displayed in Table 1.

Treatment I of reading comprehension was obtained from Harmer (1991). Treatment II was simplified at the lexical level only; while Treatment III was simplified at the syntactical level. Moreover, Treatment IV was linguistically simplified at both levels of syntax as well as vocabulary. In order to collect required data, the students in their groups were instructed to read one of the four versions of reading text. The simplification processes were carried out to cover two linguistic components: lexicon and syntax. To simplify the authentic text, a pilot group of twelve students was asked to read the authentic text and to highlight the sentences that may have complicated grammatical structures. They were further instructed to list down new words in the text. At the syntactical level, complex sentences were modified into compound or simple ones. Anaphoric expressions; such 
as still and however, were added to help the readers understand the rhetorical effect and the relationship between the pieces of information. Concerning lexical items, unknown words were replaced by their synonyms wherever required. The words that did not have relevant synonyms were treated with the rephrasing of complete sentences for clearer meaning. The synonyms and definitions were taken from the 2011 edition of Longman Dictionary.

Table 1. Type of language input —reading texts

\begin{tabular}{lllll}
\hline Treatment Type & Treatment I & Treatment II & Treatment III & Treatment IV \\
\hline Language Input & Authentic Text & Lexically Simplified Text & Syntactically Simplified Text & $\begin{array}{l}\text { Lexically \& Syntactically } \\
\text { So Simplification }\end{array}$ \\
& & & Sified Text \\
\hline
\end{tabular}

The validity of the simplified texts was established by a group of four specialists (two native speakers and other two non-native speakers) of English language. All the study groups were asked to answer the multiple-choice comprehension test comprising of 25 items, with the text in front of them during the conduct. The validity of the test was established by a group of specialists, who provided reliability (78\%) of the exam. To focus the readers' attention on the linguistic (lexical and syntactic) aspects of the text, the test contained factual and text-based questions. Conversely, the test avoided inference questions as they require focus on elaborative simplification (Yang \& Chang, 2014). Each correct answer of the test items scored one point. The groups' mean scores on the four treatments were used as indicators of language comprehensibility. Therefore, the study proposed that higher mean score is directly associated with higher level of comprehension. The one hour test was administered by the students' reading course teachers within the same setting. To investigate the influence of one independent variable with four levels (the language input in each of the four versions of reading texts) on one dependent variable (level of comprehension), the ANOVA (One-Way Analysis of Variance) was used to analyze the obtained data.

\section{Results}

Table 2 presents the reading comprehension mean scores of four treatments on 25 -item test. It shows that the students, who read the lexically simplified text, scored the highest marks $(X=12.32)$. The least mean score $(X=$ 9.68) was observed in the group, who read the authentic text. However, no significant difference has been found between the mean scores of achievement for the other two groups; their mean scores were $(X=10.00)$ and $(X=$ 10.48), respectively. Table 3 presents the result of ANOVA Test that displays the differences between the mean scores of the four treatments $(\mathrm{F}=4.426, \mathrm{df}=3, \mathrm{p}=0.006)$.

Table 2. Reading comprehension mean scores and standard deviations for the four groups

\begin{tabular}{llll}
\hline Group & N & Mean & Std. Deviation \\
\hline Authentic Text & 25 & 9.68 & 3.132 \\
Lexically Simplified Text & 25 & 12.32 & 3.038 \\
Syntactically Simplified Text & 25 & 10.00 & 2.062 \\
Lexically \& Syntactically Simplified Text & 25 & 10.48 & 2.859 \\
Total & 100 & 10.62 & 2.947 \\
\hline
\end{tabular}

Table 3. One-way analysis of variance of the reading comprehension scores for the four groups

\begin{tabular}{lllllll}
\hline & & Sum of Squares & $\mathrm{df}$ & Mean Square & F & Sig. \\
\hline \multirow{2}{*}{ Reading Comprehension } & Between Groups & 104.440 & 3 & 34.813 & 4.426 & .006 \\
& Within Groups & 755.120 & 96 & 7.866 & & \\
Score * Group & Total & 859.560 & 99 & & & \\
\hline
\end{tabular}

Table 4 displays significant statistical differences among the reading comprehension mean scores of the learners, who read the lexically simplified text (Treatment II) and those students in the other three groups. Significant statistical differences $(p=0.022)$ have been found between the mean scores of the groups, who read the syntactically simplified text (Treatment III) and that who read the authentic text (Treatment III). Table 4 further indicates that only lexical simplification had a significant positive effect on readers' comprehension; a case that has not been observed in the other three versions of the reading text. Thus, the study has identified that lexical simplification can markedly increase the comprehensiveness among the students and facilitate them in understanding their study material with efficiency. 
Table 4. Matrix of post-hoc (Tuckey) comparisons

\begin{tabular}{|c|c|c|c|c|c|c|}
\hline \multirow{3}{*}{ (I) Group } & \multirow{3}{*}{ (J) Group } & \multicolumn{3}{|l|}{ Mean } & \multicolumn{2}{|c|}{$95 \%$ Confidence Interval } \\
\hline & & Difference & Std. Error & Sig. & Lower & Upper \\
\hline & & $(\mathrm{I}-\mathrm{J})$ & & & Bound & Bound \\
\hline \multirow{3}{*}{ Authentic Text } & Lexically Simplified Text & $-2.64 *$ & .793 & .007 & -4.71 & -.57 \\
\hline & Syntactically Simplified Text & -.32 & .793 & .978 & -2.39 & 1.75 \\
\hline & Lexically \& Syntactically Simplified Text & -.80 & .793 & .745 & -2.87 & 1.27 \\
\hline \multirow{3}{*}{ Lexically Simplified Text } & Authentic Text & $2.64 *$ & .793 & .007 & .57 & 4.71 \\
\hline & Syntactically Simplified Text & $2.32 *$ & .793 & .022 & .25 & 4.39 \\
\hline & Lexically \& Syntactically Simplified Text & 1.84 & .793 & .101 & -.23 & 3.91 \\
\hline \multirow{3}{*}{ Syntactically Simplified Text } & Authentic Text & .32 & .793 & .978 & -1.75 & 2.39 \\
\hline & Lexically Simplified Text & $-2.32 *$ & .793 & .022 & -4.39 & -.25 \\
\hline & Lexically \& Syntactically Simplified Text & -.48 & .793 & .930 & -2.55 & 1.59 \\
\hline \multirow{3}{*}{$\begin{array}{l}\text { Lexically \& Syntactically } \\
\text { Simplified Text }\end{array}$} & Authentic Text & .80 & .793 & .745 & -1.27 & 2.87 \\
\hline & Lexically Simplified Text & -1.84 & .793 & .101 & -3.91 & .23 \\
\hline & Syntactically Simplified Text & .48 & .793 & .930 & -1.59 & 2.55 \\
\hline \multicolumn{7}{|l|}{ Based on observed means. } \\
\hline $\begin{array}{l}\text { The error term is Mean Square } \\
* \text {. The mean difference is sign }\end{array}$ & $\begin{array}{l}\text { ror })=7.866 \\
\text { nt at the } .05 \text { level. }\end{array}$ & & & & & \\
\hline
\end{tabular}

\section{Discussion}

Results revealed that the type of written language input influences students' comprehension in general. The mean scores of comprehension for the group, who read the lexically and syntactically simplified text was higher than that of those, who read the authentic text. The statistical analysis of data showed that the difference in the mean scores of the two groups has not been significant. The positive influence of linguistic simplification was statistically significant only in the case of lexical simplification. Accordingly, this study confirmed the results of previous research (Moradian et al., 2013) that text simplification (in general) enhances comprehensibility of SL learners. The study stated that incorporating lexical and linguistic items in the text can be helpful in exposing the learners to new material that can enhance their abilities to comprehend the content.

The students, who read the lexically simplified text, scored better on the comprehension test than those who read the authentic content, syntactically simplified text, and text containing both forms of simplification. Such result can be attributed to a set of factors. First, syntactic simplification may produce written input that differs remarkably from authentic English and may lead to the loss in meaning or message of the text (Oh, 2001). Second, the use of artificial presentation modes of meaning, shorter sentences, and repetition of words may disturb the readers' cognition and impede the comprehension. Nevertheless, the results of ineffective use of syntactically simplified input in reading instruction approve previous research findings and recommendations of researchers (Oh, 2001).

Previous research; such as Crossley et al., (2007) and Crossley, et al., (2014), argued that simplifying vocabulary can make reading texts harder to understand due to more confusing and vague words. However, this study demonstrated the opposite. The results could be attributed to the nature of the comprehension test, which concentrated on factual and referential types of questions that did not require students to go deeper in analyzing words in terms of connotation and denotation (Allington, McCuiston, \& Billen, 2015).

Similarly, other research findings showed that syntactic simplification did not lead to higher comprehension. However, despite the fact that there were no statistically significant differences between the comprehension scores of the groups, who read the authentic versus the syntactically simplified texts, the latter enhanced the comprehension of the participants. It means that splitting complex sentences into independent shorter ones made the text easier for the participants to understand. The level 2 (L2: English as second language) teachers and readers usually have two options, when choosing the reading texts: the first is the authentic text that was formed for the level 1 (L1: English as native language) language readers or the text that has been simplified linguistically to increase the comprehension (Crossley et al., 2016).

For many university students, who study English as a foreign language and part of their education requirements, reading has been considered as an important skill. The courses are usually delivered in the classrooms in the first language. It has been noted that textbooks for the daily class lectures are mostly equipped in the English language. These textbooks are those that are primarily developed for the native English speakers. Reading in English might be an ordeal for less proficient second language students because of the great amount of unknown 
vocabulary that makes it more complicated and sometimes even impossible to get the main concept of a text. Researchers have investigated many aspects of reading which include reading interest, reading comprehension, readability, text difficulty, vocabulary retention, and acquisition consequently identifying various techniques to teach second languages to the students. One of the important methods ascending to make second language reading more effective is the use of glosses in the second language as well as the first language. Many investigators have suggested various kinds of glosses that may assist reading comprehension or the acquisition of vocabulary by first language speakers or second language learners of Spanish, Korean, Russian, and Chinese. There are numerous studies that concern the effects of first language glosses. The results have revealed that the effect of first language marginal glosses was higher than in the dictionary because readers rarely use the dictionary during their reading time (Ying-Hsueh \& Good, 2009). It has been revealed that texts, which are authentic, are not always the best to present to students. Simplifying written authentic texts may facilitate the reading comprehension of English at the university level, but the use of lexically simplified texts is much more justifiable than the use of other types of text modifications. Therefore, the findings provide an empirical support to the simplified reading texts in the classroom.

Glavaš \& Štajner (2015) asserted in their study that lexical simplification plays a key role in determining the comprehensiveness of the reading material. The simple technique of replacing the complex words from the text with simple vocabulary facilitates the non-native perceivers in understanding the text. It has been identified in the study that language remodeling is primarily practiced by manual performance that may facilitate the reader with easy text to perceive and understand (Glavaš \& Štajner, 2015). Findings of this study have supported present research and have asserted lexical simplification as a helpful modality in linguistic terms, particularly for the students in engineering institutes.

The major premise is that the simpler text will be more comprehensible. It has been confirmed that simplification has a positive effect on the comprehensibility of texts. However, it cannot be said likewise that more simplification in the text can enhance comprehensiveness of second language learners. Moreover, it has been revealed that it was the type, rather than the amount of simplification that might have a higher effect on reading comprehension. The complications of segmenting the limited capacity and stream of speech in short term memory are usual weaknesses for the language learners. It is expected that the outcomes of this study will add new insights to ongoing research about the influence of the different aspects of simplification on reading comprehension. Further research in the field should go deeper in identifying the thorough types of linguistic (and elaborative) modifications that may improve the comprehensiveness of English language.

\section{References}

Allington, R. L., McCuiston, K., \& Billen, M. (2015). What research says about text complexity and learning to read. The Reading Teacher, 68(7), 491-501. https://doi.org/10.1002/trtr.1280

Crossley, S. A., \& McNamara, D. S. (2016). Text-based recall and extra-textual generations resulting from simplified and authentic texts. Reading in a Foreign Language, 28(1), 1-19.

Crossley, S. A., Louwerse, M. M., McCarthy, P. M., \& McNamara, D. S. (2007). A linguistic analysis of simplified and authentic texts. The Modern Language Journal, 91(1), 15-30. https://doi.org/10.1111/j.1540-4781.2007.00507.x

Crossley, S. A., Skalicky, S., Dascalu, M., McNamara, D. S., \& Kyle, K. (2017). Predicting Text Comprehension, Processing, and Familiarity in Adult Readers: New Approaches to Readability Formulas. Discourse Processes, 1-20. https://doi.org/10.1080/0163853X.2017.1296264

Crossley, S., Yang, H. S., \& McNamara, D. (2014). What's so simple about simplified texts? A computational and psycholinguistic investigation of text comprehension and text processing. Reading in a Foreign Language, 26(1), 92-113.

Davoudi, M., \& Yousefi, D. (2015). Comprehension Breakdown: A Review of Research on EFL Learners' Reading Difficulty and Problems, pp. 58-72.

Dell'Orletta, F., Montemagni, S., \& Venturi, G. (2014). Assessing document and sentence readability in less resourced languages and across textual genres. ITL-International Journal of Applied Linguistics, 165(2), 163-193.

Ellis, R. (2015). Understanding Second Language Acquisition. Oxford Applied Linguistics. Oxford University Press.

Glavaš, G., \& Sanja Š. (2015). Simplifying lexical simplification: do we need simplified corpora? Proceedings of 
the 53rd Annual Meeting of the Association for Computational Linguistics and the 7th International Joint Conference on Natural Language Processing, 2, 63-68. https://doi.org/10.3115/v1/P15-2011

Hoff, E., \& Core, C. (2013). November. Input and language development in bilingually developing children. Seminars in Speech and Language, 34(4), 215-226. https://doi.org/10.1055/s-0033-1353448

Mandya, A. A., Nomoto, T., \& Siddharthan, A. (2014). Lexico-syntactic text simplification and compression with typed dependencies. In 25th International Conference on Computational Linguistics.

Moradian, M. R., Naserpoor, A., \& Tamri, M. S. (2013). Effects of lexical simplification and elaboration of ESP texts on Iranian EFL university students' reading comprehension. International Journal of Psychology and Behavioral Research, 2(6), 332-338.

OH, S. Y. (2001). Two types of input modification and EFL reading comprehension: Simplification versus elaboration. Tesol Quarterly, 35(1), 69-96. https://doi.org/10.2307/3587860

Park, Y., \& Warschauer, M. (2016). Syntactic enhancement and second language literacy: An experimental study. Language Learning \& Technology, 20(3), 180-199.

Saito, Y., \& Saito, K. (2016). Differential effects of instruction on the development of second language comprehensibility, word stress, rhythm, and intonation: The case of inexperienced Japanese EFL learners. Language Teaching Research, p.1362168816643111.

Siddharthan, A. (2016). Automatic Text Simplification and Linguistic Complexity Measurements.

Woodsend, K., \& Lapata, M. (2011). Learning to simplify sentences with quasi-synchronous grammar and integer programming. In Proceedings of the conference on empirical methods in natural language processing (pp. 409-420). Association for Computational Linguistics.

Ying-Hsueh, C., \& Good, R. L. (2009). L1 glosses: Effects on EFL learners' reading comprehension and vocabulary retention. Reading in a Foreign Language, 21(2), 119-142.

Zhang, X., \& Lapata, M. (2017). Sentence Simplification with Deep Reinforcement Learning. arXiv preprint arXiv:1703.10931.

\section{Copyrights}

Copyright for this article is retained by the author(s), with first publication rights granted to the journal.

This is an open-access article distributed under the terms and conditions of the Creative Commons Attribution license (http://creativecommons.org/licenses/by/4.0/). 